\title{
"Que tenga un pequeño jardín de flores". Una experiencia participativa entorno al turismo y el patrimonio cultural en el Impenetrable chaqueño
}

\section{"Wish it had a small flower garden". A participatory experience around tourism and cultural heritage in the Impenetrable Chaco}

\author{
Gabriela Barrios ${ }^{1}$, Marcos Monsalvo ${ }^{2}$ y Marcelo Pérez ${ }^{3}$ \\ Recibido: 21/11/2021. Aceptado: 30/03/2021. \\ http://dx.doi.org/10.30972/dpd.10154807
}

\section{Resumen}

En este artículo presentamos avances de una experiencia aún en proceso, que se desarrolla en un paraje rural del Impenetrable chaqueño, al nordeste de la República Argentina. Desde un enfoque político metodológico inspirado en la Educación Popular y en la Investigación Acción Participativa, este proyecto aborda la memoria y el patrimonio cultural como estrategias para fortalecer la organización de la comunidad local en un contexto de fuerte impacto de políticas de turistificación. Puesto que, en los últimos años, junto a la creación del Parque Nacional Impenetrable, se inició el desarrollo del Master Plan Impenetrable con financiamiento del Banco Interamericano de Desarrollo, coordinado primero por una Unidad Ejecutora y desde 2019 por el Instituto de Turismo provincial, describimos de manera densa el proceso que transita la comunidad hasta tomar la decisión de reconstruir la antigua escuela del paraje. Acción que cobra real importancia porque la comunidad ve en ella, además de la posibilidad de conservar un edificio que les identifique para recibir a las y los visitantes, la oportunidad de fortalecer sus vínculos, de tener una motivación para organizarse, para unirse en un sitio común y a través de unas memorias compartidas que les son significativas, posicionarse de manera más sólida en las negociaciones a las que se ve obligada a partir de este nuevo contexto. Estos sucesos trajeron consigo, entre otras cosas, tensiones y disputas por el uso y la tenencia de la tierra, que hasta hace pocos años era ocupada históricamente por familias asentadas en el lugar desde las primeras décadas del siglo XX.

Palabras clave: memorias/patrimonio cultural, participación, turismo.

\footnotetext{
${ }^{1}$ María Gabriela Barrios - Facultad de Humanidades -UNNE- e Instituto de Cultura del Chaco- Lic. Trabajo Social- Mgter. Políticas Sociales - rriosba@gmail.com

${ }^{2}$ Marcos Monsalvo Ricci- Facultad de Arte y Ciencias de la Cultura -UNNE- e Instituto de Educación Superior

"Rodolfo Walsh"- Músico - Mgter. en Estudios Culturales - marcosmonsalvo@gmail.com

${ }^{3}$ Marcelo Pérez - Instituto de Cultura de Chaco - Técnico en Comunicación Social.
} 


\section{Abstract $^{4}$}

In this article we present advances of an experience that is still in process, which takes place in a rural area of the impenetrable chaqueño, northeast of the Argentine Republic. From a political methodological approach inspired by Popular Education and Participatory Action Research, this project tackle memory and cultural heritage as strategies to strengthen the organization of the local community in a context of strong impact of tourism policies. In recent years, together with the creation of the Impenetrable National Park, the development of the Impenetrable Master Plan began with financing from the Inter-American Development Bank, coordinated first by an Executing Unit and since 2019 by the provincial Tourism Institute. We describe in a dense way the process that the community goes through until it makes the decision to rebuild the old school in the area. Action that takes on real importance because the community sees in it, in addition to the possibility of preserving a building that identifies them to receive visitors, the opportunity to strengthen their ties, to have a motivation to organize, to join in a place common and through shared memories that are meaningful to them, position itself more solidly in the negotiations to which it is forced from this new context. These events brought with them, among other things, tensions and disputes over the use and ownership of the land, which until a few years ago was historically occupied by families settled in the place since the first decades of the 20th century.

Keywords: memories/cultural heritage, participation, tourism.

\section{Introducción}

A lo largo de este trabajo compartimos avances de una experiencia, aún en proceso, que se desarrolla en un paraje rural del Impenetrable chaqueño, La Armonía. Allí viven unas catorce familias criollas. Este paraje pertenece al ejido municipal de Miraflores, distante a 115 kilómetros de Juan José Castelli, ciudad cabecera del departamento Güemes, en la provincia del Chaco, al nordeste de la República Argentina.

La creación del Parque Nacional El Impenetrable ${ }^{5}$, cuyo ingreso principal se encuentra justamente en La Armonía, trajo consigo diferentes intervenciones relacionadas con el desarrollo turístico de la zona, tanto estatales como privadas. El Estado provincial proyectó el Master Plan Impenetrable con intención de desarrollar una visión integral sobre la región, pero con eje en la potencialidad turística natural y cultural.

Tanto este master plan como la mayoría de las organizaciones e instituciones vinculadas al mismo y a la actividad turística en general proponen que las poblaciones locales de criollos e

4 Agradecemos a Aramí Monsalvo del Cid por colaborarnos con la traducción al inglés.

5 Inaugurado oficialmente en 2017. 
indígenas se organicen para ofrecer a las y los turistas expresiones y saberes propios de su cultura, tales como: gastronomía tradicional, artesanías, música, fiestas populares, conocimientos de su territorio relacionados con el monte, el río, los usos de plantas medicinales y alimenticias. Es decir, promueven un enfoque que pone en evidencia la compleja y problemática vinculación entre turismo, naturaleza y cultura, y las diversas maneras en que estas tensiones afectan la vida cotidiana de las comunidades.

En todas las etapas de implementación de estas iniciativas, los procesos de consulta comunitaria aparecen como requisitos cumplimentados, sin embargo, la gran extensión del territorio involucrado desdibuja la efectividad de las mismas. Por ejemplo, el plan de obras impacta en varios municipios, localidades, como así también en parajes rurales; la consulta general aprueba las mismas, pero la localización específica de cada instancia vuelve a generar tensiones en los pobladores inmediatos.

Con relación a estos procesos de promoción de una oferta cultural local para atraer al turismo, en mayo de 2019 comenzamos a implementar el proyecto Trenzar nuestras memorias, decidir nuestros presentes, soñar nuestros futuros ${ }^{6}$, en los parajes La Armonía y Las Hacheras ${ }^{7}$.

En una primera etapa del proceso, de mayo a septiembre de 2019, nos planteamos trabajar en la reactivación de las memorias compartidas y colectivas de la comunidad, sus configuraciones y las implicancias en la vida cotidiana, y de manera colaborativa identificar datos que ayuden a configurar la historia o las historias del paraje, sus procesos de poblamiento, hechos significativos, sus referentes comunitarios, sus conflictos y sus logros. Para que sean las propias comunidades las que decidan qué quieren compartir, cuándo, cómo y con quiénes, asumimos que se deben garantizar espacios de participación y consulta reales, por lo cual nos propusimos facilitar espacios de diálogo y dinámicas participativas para trabajar junto con las y los pobladores en torno a los siguientes interrogantes: quiénes somos; de dónde venimos; dónde estamos; por qué estamos como estamos (definiendo responsables externos e internos); qué sabemos; qué hacemos; hacia dónde queremos ir; conservando y cuidando qué; recuperando qué; qué de todo esto queremos compartir con

\footnotetext{
${ }^{6}$ El mismo surge por iniciativa del Departamento de Patrimonio Cultural Inmaterial del Instituto de Cultura del Chaco, en articulación y cooperación con el Instituto de Turismo del Chaco y el Parque Nacional El Impenetrable. Las tres instituciones dispusieron de personal interno para concretar el trabajo en terreno y de recursos financieros -o su gestión- para la contratación de un especialista en procesos participativos. El equipo de coordinación realizó las tareas de manera conjunta, definiendo colaborativamente varios aspectos del proceso que se expone en este trabajo. Entre el Instituto de Turismo y Parques Nacionales se concentró la convocatoria comunitaria, el diseño metodológico en el consultor externo y el registro audiovisual y fotográfico en Instituto de Cultura. Sin embargo, en cada uno de los encuentros los aportes de todos confluyeron en la concreción de las acciones. Mencionamos a los y las integrantes del equipo: Joni Marcelo Torres, Mariela Marcón, Ingrid Breibach, Antonio Báez y dos de los autores de este artículo. Este artículo está escrito además por una externa al equipo coordinador, que en esos meses ocupó un cargo de gestión política en una de esas instituciones.

${ }^{7}$ El proyecto se desarrolla en simultáneo también en Las Hacheras, paraje distante a $50 \mathrm{~km}$, pero de mayor tamaño (100 familias). En este artículo decidimos solo presentar el proceso de La Armonía.
} 
visitantes y qué no. Esto lo desarrollamos en jornadas intensivas de trabajo y compartires en las que participaron un promedio de veinte personas del lugar de diferentes edades, incluidas/os niñas y niños.

Estos encuentros permitieron la identificación colectiva de algunas líneas de acción que se expresan en el deseo de la comunidad de reconstruir la antigua escuela del paraje, decisión que cobra real importancia porque la comunidad ve en ella, además de la posibilidad de conservar un edificio que les identifique para recibir a las y los visitantes, la oportunidad de fortalecer sus vínculos, de tener una motivación para organizarse, para unirse como vecinos y vecinas en un sitio común a través de unas memorias compartidas que les son significativas, y posicionarse de manera más sólida en las negociaciones a las que se ve obligada a partir de este nuevo contexto marcado por diferentes intervenciones relacionadas a procesos de turistificación. Esto marca el comienzo de una segunda etapa que se inicia en octubre de 2019 y continúa hasta la actualidad (año 2021).

\section{El Impenetrable: breve historicidad y complejidades sociopolíticas}

La provincia del Chaco tiene una fuerte vinculación a nivel nacional con el imaginario en torno de "El Impenetrable". Geográficamente se refiere al territorio ubicado al noroeste de la provincia. La denominación hace referencia a la espesura "original" de su monte y la fauna que habitaba en toda esa extensión. Sin embargo, este nombre también se asoció a la idea de "desierto" porque allí "no había población", invisibilizando a los pobladores indígenas qom y wichi y operó como justificador durante un importante período de la ausencia estatal en el acceso a los servicios de salud, educación, comunicación y transporte público.

Además de la población wichi, este territorio alberga a criollos cuyos ancestros se trasladaron desde Salta mayoritariamente, vinculados a las tareas ganaderas, y "gringos" o "blancos" centrados en actividades comerciales y administración estatal.

Este espacio ha tenido, desde la formación del Estado-nación, diferentes momentos en los que centró su atención en esta porción territorial. El inicio del primer momento puede ser identificado sobre fines del siglo XIX, con la ocupación efectiva del Chaco argentino que el Estado nacional realiza a partir de campañas militares y la consolidación de la "línea de fortines". Una segunda avanzada del Estado se produce en la década de 1970: el Chaco se había provincializado en 1951, es entonces la provincia la que proyecta una expansión hacia El Impenetrable, teniendo como foco la extensión de la frontera agrícola-forestal y el proceso colonizador. Luego, podemos señalar en los últimos 15 años, un nuevo avance a través de la frontera agrícola con la producción de soja, lo que hizo que tanto la actividad algodonera como la ganadera buscarán nuevas tierras, produciéndose un renacer del interés sobre El Impenetrable desde ese sector.

En paralelo, las reivindicaciones indígenas por la restitución de sus tierras fueron adquiriendo mayor relevancia: de las entregas de parcelas agrícolas individuales, seguidas por las 
propiedades comunitarias, a la reivindicación de territorios continuos ${ }^{8}$. Estos últimos procesos se dan dentro de la gran zona llamada "Impenetrable", y en cada experiencia surge un sinnúmero de problemáticas respecto de la ocupación y gestión del territorio, la seguridad de sus límites y dentro del mismo, la tensión entre propiedad privada-comunitaria y responsabilidad estatal. Asimismo, la visión pública del "enfrentamiento" entre quienes defienden sus derechos: indígenas y no-indígenas.

En este contexto surge el proyecto de creación del Parque Nacional El Impenetrable. El mismo ha sido promovido sobre las tierras de la estancia La Fidelidad, tanto por el gobierno del Chaco y la Administración de Parques Nacionales como por diversas organizaciones ambientalistas de la Argentina. Su creación ha sido posible gracias a los aportes de empresas, organizaciones no gubernamentales (ONG) -CLT (The Conservation Land Trust), entre ellas- y ciudadanos argentinos y extranjeros, por eso se considera que es el primer parque nacional impulsado por la gente a través de un proceso participativo. En 2011, cuando fue asesinado el último propietario de la estancia (territorio ocupado desde 1872) ${ }^{9}$, organizaciones ambientalistas y la Administración de Parques Nacionales propusieron crear un parque nacional y fue la provincia del Chaco quien movilizó el aparato administrativo y legislativo para llevar adelante esta propuesta.

El Estado provincial proyectó el Master Plan Impenetrable, con intención de desarrollar una visión integral sobre la región, pero con eje en la potencialidad turística -natural y cultural. El Master Plan podría ser pensado, en la actualidad, como una nueva avanzada de apropiación y consolidación territorial que se identifica con el desarrollo del capitalismo a través de la actividad turística en la región. Cuenta con financiamiento del BID y -como todo proyecto internacional- asume la consulta a las comunidades como requisito ineludible para su ejecución. La tensión entre ese requisito y las estrategias de consulta y/o instancias de participación de las comunidades es el eje de estas experiencias.

\section{Posicionamientos conceptuales y políticos}

Las metodologías participativas implican una difícil tarea: desenvolverse simultáneamente en un todo único, entre la acción y la reflexión, entre la práctica y la teoría. Es por esto que, siguiendo a Daniel Mato (2002: 33), resulta pertinente reflexionar

\footnotetext{
${ }^{8}$ Dos restituciones: 150.000 hectáreas en el Teuco Bermejito a la Asociación Meguesoxochi (1999) y 300.000 hectáreas de la denominada Reserva Grande (2018), entrega del título efectivizada en fracciones de 100.000 hectáreas a cada etnia (moqoi, wichí y qom).

${ }^{9}$ La estancia fue entregada por el gobierno salteño (en aquel entonces aún no existía el Chaco como provincia) a Natalio Roldán, comerciante de Buenos Aires, por sus méritos en la navegación y exploración del río Bermejo. Luego, la estancia fue vendida a la familia Born, que la transformó en un establecimiento ganadero. Más tarde, los hermanos Roseo continuaron con esa misma actividad, aunque con menor ganancia económica. Esta situación los llevó a comenzar con la extracción maderera, básicamente de algarrobo, para su industrialización en Castelli.
} 
[no sobre] ¿qué investigo? sino ¿para qué investigo?, y también acerca de si investigo "sobre" ciertos actores o grupos sociales, o "con" esos actores o grupos sociales, al menos como proyecto y dependiendo de los actores. Estas dos últimas preguntas son de carácter ético y político, y ellas condicionan de entrada las preguntas de investigación, la aproximación epistemológica, la elaboración teórica y los planteos de método.

Estamos refiriendo entonces a responsabilidades y compromisos éticos y políticos delicados. Orlando Fals Borda (1991: 15) explica el reto que ofrece el concepto de "participación" diciendo que lo esencial es el "modo de ver nuevo" y en cierta medida "ver de nuevo". Sostiene que para entender esta concepción hay que entrar en el campo de las actitudes. Este marco de subjetividades es cuestionado por la tesis de neutralidad valorativa a la que adhieren algunos científicos sociales; ante esto, Fals Borda (1991: 16) plantea la noción de "compromiso":

El concepto de compromiso, dentro de las ciencias sociales, viene a demostrar que la ciencia no es un fetiche con articulación propia y autónoma del conocimiento, sino que es un producto cultural, que está sujeta a las actitudes, a las creencias, a las supersticiones inclusive, de los científicos, es decir, de aquellos que hacen ciencia.

Tomás Rodríguez Villasante (2019) y el equipo de la Red Cimas sostienen que las metodologías participativas se distinguen por su perspectiva dialéctica, que "parte de la consideración del objeto a investigar como sujeto (protagonista de la investigación) y en la que la finalidad de la investigación es la transformación social. Utiliza algunas técnicas específicas propias, pero sin rechazar el uso de las técnicas cuantitativas y cualitativas" (Rodríguez Villasante, 2019: 125).

Adhiriendo a estas perspectivas, concebimos nuestro rol como equipo coordinador desde un lugar de facilitación y acompañamiento del proceso investigativo, en sintonía con maneras de entender a la IAP como un tipo de investigación que

está asociada a la búsqueda de una comprensión crítica de la realidad, vinculada a una exploración por construcción de dignidad, justicia, solidaridad, poder; una investigación que está planteada desde el pensar y actuar con otros sobre la realidad social a cambiar, estableciendo una ruptura con las epistemes del pensar sin el otro, por el otro o para el otro. Epistemes hegemónicas que silencian, someten, oprimen al establecerse desde certidumbres, dogmas y autoritarismos. (Ghiso, 2016: 72)

Alfredo Ghiso $(2017)^{10}$ nos propone sentipensar la participación como solidaridad con el otro, el desafío de construir una episteme solidaria que construye conocimiento con el otro, que

\footnotetext{
${ }^{10}$ Charla en el marco de las "Jornadas de Patrimonio y Participación: Encuentro convivencial de experiencias colombianas y argentinas", realizadas en Medellín, Colombia, del 7 al 9 de junio de 2017.
} 
decide junto a otros, no solamente hacia dónde ir, sino también las maneras de transitar ese camino. Una episteme del nosotros, nos seguirá diciendo este autor, es solidaria y decolonial, se levanta contra quienes nos interpretan, nos explican, nos deciden, nos actúan, es un ejercicio emancipatorio, dialógico, colectivo. Argumenta que, concebido de esta manera, todo proceso participativo es formativo, puesto que a la vez que nos posibilita asumirnos como sujetos de derecho, de conocimiento, de poder, necesariamente también reconoce la otredad, la diferencia y la desigualdad.

Decidimos compartir esta experiencia a partir de una descripción densa del proceso vivenciado y de un detalle de las estrategias metodológicas adoptadas y de las técnicas utilizadas, porque, para nosotros, está claro que el proceso participativo mismo fue definiendo estos pasos. La sistematización de cada encuentro posibilitó pensar en el siguiente. El proceso que presentamos de implementación de distintas técnicas de activación de las memorias colectivas y compartidas fundamenta su sentido porque es indiscutible que en torno a ellas las comunidades "construyen sus sentidos de pertenencia, se cohesionan como entidad social y despliegan sus relaciones y prácticas presentes" (Goff, 1994, cito en Cendales y Torres, 2001: 67). Enmarcamos nuestra estrategia metodológica en la Recuperación Colectiva de la Historia $(\mathrm{RCH})$, propuesta investigativa imbricada a los trayectos históricos de la IAP que, como lo afirma Fals Borda (1985), pertenece a una genealogía latinoamericana propia, ligada a importantes antecedentes en la teoría y en la praxis: las teorías de la dependencia y de la explotación, la contrateoría de la subversión y la teología de la liberación, la educación popular, la investigación temática y las técnicas dialógicas, la reinterpretación de las tesis del compromiso y neutralidad de los científicos, tomadas de Marx y Gramsci, entre otros. La RCH es un enfoque investigativo que promueve

una modalidad de producción de conocimientos que busca re-construir la historia/memoria de hechos y procesos compartidos por colectivos populares (organizados o no) involucrando activamente a sus protagonistas [...] la RCH busca fortalecer procesos de identificación y organización colectiva (Cendales y Torres, 2001: 67).

Asumimos la memoria como una práctica, como un ejercicio colectivo que implica reflexiones en torno a qué se recuerda y qué se olvida (sean estos olvidos voluntarios, involuntarios o provocados), implica también disputas políticas referidas a qué se narra de lo que se recuerda y cómo se construye este relato. En estas jornadas y encuentros no buscamos convergencias en torno a "la verdad" de los procesos históricos, sino la escucha de todas las voces posibles.

Los trabajos de memorias colectivas -y por ende las identidades- no se circunscriben a "la cultura", es otra tentación recurrente asociarlas a un concepto reduccionista e idealista de la misma, minimizando su sentido en la reproducción social en tanto productora de significaciones de la vida social (García Canclini, 2004). En esta perspectiva, cultura, identidad 
y memoria son procesos indisolubles y no hay dudas que son campos de luchas simbólicas y de lucha política.

La memoria es una relación intersubjetiva, elaborada en comunicación con otros y en determinado entorno social. En consecuencia, sólo existe un plural. La pluralidad de memorias conforma un campo de batalla en que se lucha por el sentido del presente en orden a delimitar los materiales con los cuales construir el futuro. A la luz del presente las memorias seleccionan e interpretan el pasado. (Lechner, 2002: 62)

La experiencia que presentamos nace desde la irrupción de los proyectos de desarrollo turísticos en pequeñas comunidades. Las perspectivas de "turismo comunitario" y "turismo cultural" van generando una inquietud y una demanda respecto de los procesos de patrimonio cultural: las manifestaciones y prácticas culturales específicas de estas comunidades. Por un lado, las instituciones estatales debieran generar procesos de salvaguardia ante el posible impacto turístico; pero, a su vez, y por otro lado, el interés desde las mismas se fortalece por su "necesidad" de integrarlas al "proceso de desarrollo turístico". En ese punto, las políticas de fortalecimiento turístico pueden entrar en tensión con las de protección del patrimonio cultural.

Pretendemos explicitar esa tensión y, asimismo, exponer cómo desde el proceso centrado en "lo patrimonial" accedimos a disputas concretas e históricas: la tierra y la fuente de derechos de su ocupación. Entendemos que las diferentes aristas del proceso que compartimos en este artículo permiten visualizar la relación entre memorias y construcción de identidades colectivas, y las resignificaciones constantes con relación al contexto: relaciones con el territorio y con otros sujetos y los poderes que detentan.

\section{La vieja escuela: lugar de encuentro de la memoria colectiva}

Las limitaciones de accesibilidad al territorio nos condicionan la posibilidad de llevar adelante un proceso de cercanía cotidiana. Por esta razón, diseñamos una estrategia metodológica basada en jornadas y encuentros mensuales que, a partir de técnicas participativas lúdicas y dinámicas, nos permitieron un compartir intensivo. Entre mayo y septiembre de 2019 se concretaron tres jornadas de trabajo que marcaron una primera etapa del proceso. Las mismas fueron diseñadas y desarrolladas desde una mirada inspirada en los enfoques de la Investigación Acción Participativa (IAP) y de la Educación Popular. Asimismo, en estas jornadas buscamos articular tareas con pobladores/as interesados/as en continuar indagando e incorporando datos e información significativa entre encuentro y encuentro. Una suerte de "grupo motor"11", aunque espontáneo y sin la posibilidad de realizar "escuelas de formación

\footnotetext{
${ }^{11}$ En algunos ámbitos relacionados a la IAP se llama grupo motor al equipo que se conforma con distintos actores locales y otros vinculados a la temática, que tienen incidencia en el territorio y la problemática convocante. En este caso, algunos/as pobladores/as se incorporaron al proceso de investigación comprometiéndose a realizar entrevistas a pobladores antiguos que no asistieron a los encuentros, para indagar en aspectos, hechos y datos de
} 
metodológica $^{12 " . ~ E l ~ t r a b a j o ~ i n t e n s o ~ d e s a r r o l l a d o ~ d u r a n t e ~ m a y o ~ y ~ s e p t i e m b r e ~ p e r m i t i o ́ ~}$ identificar de manera colectiva algunas líneas de acción que marcaron el comienzo de la segunda etapa, que se inicia en octubre de 2019 y continúa hasta la actualidad (año 2021).

Las convocatorias a los encuentros fueron realizadas a través de la radio comunitaria del paraje Las Hacheras y de otras con llegada a la zona. También con el "de boca en boca", a través de agentes del Parque Nacional El Impenetrable y del Instituto de Turismo, de referentes de la comunidad y por mensajes de WhatsApp. La mayoría de las actividades relacionadas a este proyecto las desarrollamos en las instalaciones de la EEP No 362 Fernando Ramón Salcedo ${ }^{13}$.

Las jornadas se desarrollaron de 9 a 17, aproximadamente. Las mismas incluyeron momentos de alimentación y descansos comunes, que fueron importantes para la creación de lazos de confianza entre el equipo de trabajo y la comunidad, indispensables para la continuidad del proceso. Es durante los almuerzos que pudimos identificar a aquellas personas interesadas en realizar tareas de indagación, entrevistas a antiguos pobladores y búsqueda de documentos históricos y familiares.

A estos encuentros asistió un promedio de veinte personas, pobladores y pobladoras del paraje de distintas edades: jóvenes, adultos/as mayores, niños y niñas de la escuela. Además, se sumó un antiguo poblador que ya no vive en el lugar y, en ocasiones, participó también un integrante de una ONG con presencia en el territorio.

Durante todas las jornadas, un integrante del equipo coordinador fue desarrollando una relatoría de los momentos más significativos. Esto lo hicimos en un papelógrafo a la vista de todos los participantes. También se efectuaron registros audiovisuales y fotográficos, que son materia prima para realizar un documental audiovisual de todo el proceso.

Compartimos una síntesis gráfica de la secuencialidad del proceso de la Etapa 1, que se describirá en detalle en los apartados que siguen.

\footnotetext{
interés que emergieron en las dinámicas participativas de los encuentros. Asimismo, se ocuparon de buscar fotografías y documentos históricos, familiares y comunitarios relevantes para la reconstrucción de la historia del paraje.

${ }^{12}$ En las experiencias de IAP llevadas adelante por Fals Borda y en otras experiencias de investigadores e investigadoras vinculadas a estas trayectorias, se incluyen talleres de formación metodológica y de apropiación de técnicas y herramientas de investigación para trabajar con las personas interesadas en integrar estos grupos motores.

${ }^{13}$ Queremos agradecer especialmente a Santos Bogado, Nancy Cornú y Jorge Luna por ser motores del proceso en su comunidad. Y a Juana Galván por facilitarnos las instalaciones de la escuela y apoyar este proceso.
} 


\section{ETAPA IO}

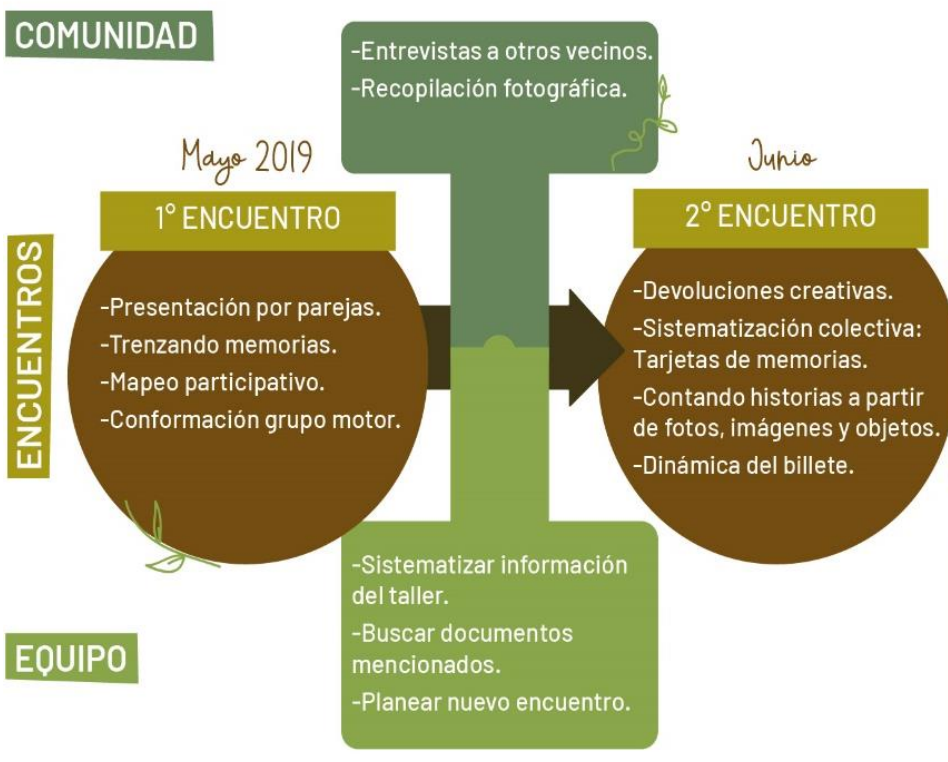

\section{Primer encuentro}

Iniciamos la primera jornada con una dinámica basada en una adaptación de la técnica "Presentación subjetiva por parejas ${ }^{14 ",}$ de la que surgieron: "la importancia de escuchar al otro", "expresarse ante el otro", "valorar lo positivo que tengo y conocer lo bueno de mi vecino/a" e identificar datos históricos compartidos.

Continuamos con un ejercicio que se denominó "Trenzando Memorias" ${ }^{15 "}$. En el transcurso del mismo propusimos tejer memorias individuales y colectivas con retazos de telas. Implica un primer momento práctico individual que apunta a la recreación de memorias personales.

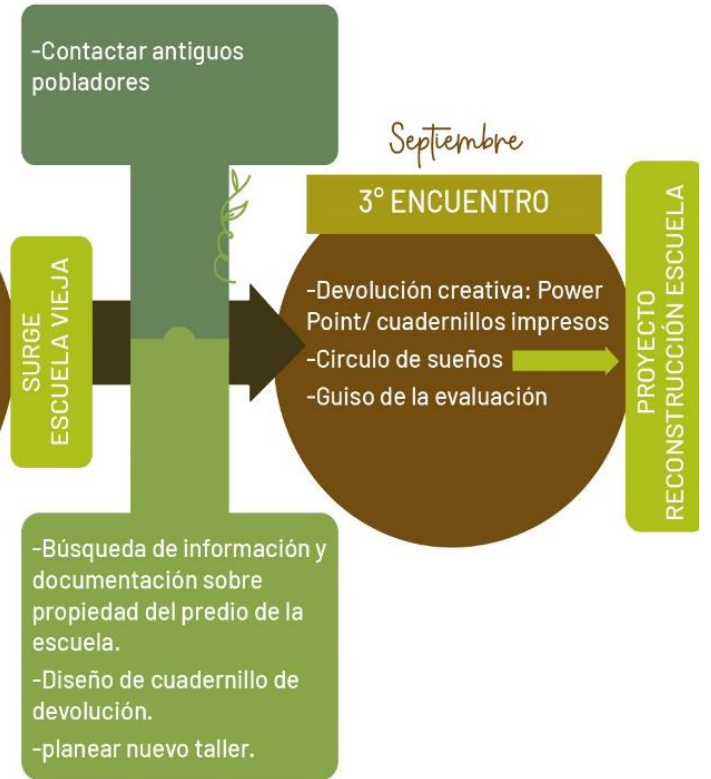

\section{PRESENTACION EN PAREJAS}

- Cada participante en el rol de "entrevistador" o de "periodista", preguntara a quien tiene al lado lo siguiente: Nombre y Apellido; ¿Por qué vino al taller?; ¿Qué es lo que más le gusta y mejor sabe hacer?; ¿De dónde vinieron sus ancestros?; ¿Cuál es el hecho más importante que recuerda en relación al paraje? (este hecho puede ser reciente o lejano en el tiempo).

- En ronda, cada pareja se presenta de forma cruzada (el entrevistador/a presentó a su entrevistado/a)

- Registro en papelógrafos de la información más relevante en términos de datos históricos, oficios y saberes, potencialidades.

- En plenario, recuperación colectiva del sentido de la dinámica.

\footnotetext{
${ }^{14}$ Ver Vargas, Bustillos y Marfán (1987), Tomo I, Animación 1.1.

${ }^{15}$ Agradecemos al profesor Hamilton Suarez Betancur (Medellín, Colombia) por compartirnos este ejercicio en un taller brindado en el Centro Educativo Franciscano Intercultural Bilingüe UEP 72 Cacique Pelayo, en la ciudad de Fontana, Chaco, junio de 2018. Asimismo, por su asesoramiento para la adaptación de esta dinámica para la implementación en nuestro proyecto.
} 


\section{TRENZANDO MEMORIAS}

- Plasmar en un trozo de tela una forma, palabra, frase, imagen o dibujo, que simbolice algún recuerdo personal significativo.

- Unir, con hilo y aguja, cada pedazo de tela, creando un conjunto, un "todo".

- Exposición de manera tal que los asistentes pudieron apreciar la construcción colectiva del tejido a modo de mural o tapiz.

- Propiciamos un momento reflexivo, de interpretación de las formas y texturas de la construcción colectiva.

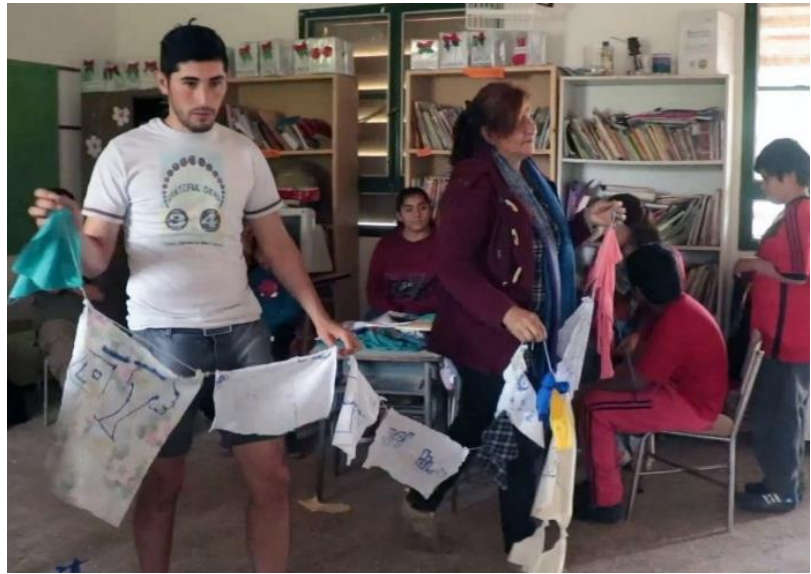

Los/as coordinadores/as tomamos las formas, texturas y escrituras simbólicas de las memorias para lograr, a partir de preguntas guías dirigidas al grupo, una reflexión sobre sus concepciones, nociones y construcciones sociales y culturales. Para ello, nos apoyamos en el ejercicio práctico, haciendo una identificación de cada "retazo" y del tapiz en su conjunto. Las diferentes texturas de las telas y la variedad de formas y dibujos creados permitieron reflexionar sobre la diversidad en torno a la memoria, los espacios entre retazos sobre los olvidos, los tipos de olvidos, la metáfora del tapiz permitió sentipensar la manera en que se construye la memoria colectiva y la importancia en que todas las memorias estén incluidas en la misma.

Para continuar, en conjunto con los participantes decidimos trabajar en la realización de mapeos participativos. Esta actividad resultó muy enriquecedora, pues la misma permitió la identificación de lo que luego los participantes llamarían "lugares trascendentales": la escuela vieja del maestro Salcedo, los cementerios familiares, la pista de aviación, la cancha de carreras de caballos, el corral comunitario, la vieja barraca de don Silva, los pozos de agua en el río, etc. También se identificaron en el mapeo a los pobladores más antiguos, portadores de memoria, a quienes los participantes se propusieron entrevistar entre encuentro y encuentro.

Como ya se anticipó, la estrategia que se intentó aplicar para incorporar testimonios y opiniones de personas que no asistieron al encuentro fue conformar un grupo de interesados con algunos de las y los participantes del primer encuentro, quienes se encargaron de entrevistar a estos pobladores antiguos que no asisten al espacio colectivo, de conseguir fotos, documentos y recortes de diarios significativos, etc. (archivos de baúl). Si bien creemos que fue insuficiente y que esta tarea se puede profundizar, se pudo obtener algunas aproximaciones al origen del nombre del paraje a partir de las entrevistas a los antiguos pobladores que realizaron algunos participantes del encuentro.

Por otra parte, el equipo coordinador se abocó a transcribir los registros obtenidos y a aportar información de otras fuentes. En este sentido, fue muy importante el trabajo Experiencias de un Maestro Rural, de Fernando Ramón Salcedo (1978), maestro en La Armonía 
entre 1946 y 1968 que marcó la vida comunitaria de estos parajes y que es recordado de manera entrañable por la comunidad.

A partir de todo este material de registro, planificamos la siguiente jornada de trabajo para el mes de junio. Con la intención de seguir profundizando en las memorias compartidas del paraje y en las prácticas culturales de sus pobladores, confeccionamos distintas tarjetas con los datos y relatos registrados y diseñamos una estrategia para organizarlas y clasificarlas por ejes temáticos de manera participativa ${ }^{16}$.

\section{Segundo encuentro}

La primera parte de esta jornada tuvo como propósitos revisar, ampliar y sistematizar, de manera colaborativa, la información obtenida en la primera. Para esto, dispusimos las tarjetas mezcladas en una mesa al centro del salón y solicitamos a las y los participantes que las agrupen de acuerdo a criterios que discutan y acuerden entre ellas y ellos.

En una primera instancia, la información quedó

TARJETAS DE MEMORIAS organizada en los siguientes ámbitos: "Recordatorios de las primeras memorias";

- Las tarjetas se fueron pegando en la pared, organizadas en columnas según criterios acordados.

"Primeros pioneros del paraje"; "Oficios legados"; "Lugares trascendentales"; "Nuestros ancestros".

-Se conforman ejes temáticos a través de los cuales se organizaron los relatos y datos históricos recopilados.

A continuación, compartimos algunos ejemplos de los datos y relatos que se consignaron de manera colectiva en dos de estos ámbitos.

- A partir de una discusión en plenaria, se nombró cada columna consensuando una conceptualización.

- Asi se organizaron esas memorias por ámbitos.

\section{"Recordatorios de las primeras memorias":}

Cuando Don Silva llegó no había nada en el paraje. Llegaron antes de 1940. Dónde están las ruinas de la Escuela Vieja solo había un techito. Jorge Silva era de Santa Fe, era vendedor, sabía mucho de leyes, fue gerente de un banco.

Cuando era niño había familias aborígenes wichí, algunos de apellido Arias, estaban al costado de la cancha de aviación. Jugábamos al fútbol, con ellos aprendí a nadar.

Se recuerda al Gaucho Parada: Un hombre que era perseguido por la policía y la gente del lugar lo defendía. Fue asesinado dentro de lo que hoy es el Parque Nacional. Es posible que Parada haya matado al abuelo de Bogado.

En el verano de 1952 hubo grandes lluvias que abrieron correderos y comenzó a entrar agua del río Teuco. A partir de allí el Bermejito dejó de ser el "Río Seco". Antes sólo tenía agua durante los meses de verano cuando llovía mucho en Salta. Solo duraba unos meses, luego sólo quedaban unos pozos con agua hasta que al cabo de dos o tres meses se secaban también. (Memorias del maestro Salcedo)

\footnotetext{
${ }^{16}$ Un especial agradecimiento a María Lila Bina y a Marilí Garrafa por ayudarnos a diseñar esta estrategia y a confeccionar las tarjetas.
} 
Se construye una pista de aterrizaje. El 29 de agosto de 1959 aterriza el primer avión. Un avión de la Asociación Gabriela Mistral de Castelli, durante dos horas paseó a todo el pueblo. Se consigue un equipo de onda corta para comunicarse con radioaficionados de Castelli. Luego se compra un grupo electrógeno. (Memorias del maestro Salcedo)

\section{"Lugares trascendentales":}

Se consignan lugares y sitios significativos y simbólicos para la vida de la comunidad. En términos de reconstrucción histórica y de usos sociales de la actualidad: Escuela Vieja (donde enseñó el maestro Salcedo), pista de aviación, los cementerios ("cada familia tiene su propio cementerio"), Barraca de Jorge Silva (lugar de trueque y encuentros, terrenos cedidos por los Frías), pozo de los Bogado (lo limpiaron durante la sequía de 2013 para tener agua), corral comunitario, cancha de carreras cuadreras, La Pérgola (construida en tiempos recientes), cancha de fútbol (Registro de aportes colectivos).

Además, quedaron grupos de tarjetas para los cuales no se llegó a consensuar un nombre. En uno de ellos se consignaron celebraciones, fiestas, juegos y rituales que marcan la vida colectiva del trabajo, la religión u otras prácticas de la vida comunitaria como, por ejemplo:

fiestas patronales (santeadas y peregrinaciones) que hace 15 años se dejaron de hacer; carrera de caballos; hacer "vivar" los caballos; largas procesiones para que llueva; coplas; juego de Sortija; fútbol entre amigos. (Registro de aportes colectivos)

Y en otro se consignaron saberes y técnicas artesanales, tales como:

tejer con lanas; construcciones con techos de tierra o de tejas de palma; paredes de palo a pique o enchorizados de aibe; fabricación de vestimentas de cuero para atenuar los azotes de las ramas y espinas del monte: sombrero retobado, guardacalzón, coleto (saco de cuero crudo), guardamonte, polainas, espuelas, lazo y patero (lazo más corto); fabricación y uso de colchones de lana de oveja; catres de tiento; cosecha y aprovechamiento de seis tipos de miel del monte; elaboración de quesos, dulces (Doca), de aloja y guarapo; caza del quirquincho: se marisca a fines de julio principios de agosto. En época de celo no se caza; en septiembre no se pueden cazar guazunchos porque tienen crías. (Registro de aportes colectivos)

Una vez que se ordenaron todas las tarjetas en la pared, discutimos si los datos ubicados en los ejes eran correctos, si había información que corregir y o que agregar en alguno de los ejes. En función de esta reflexión y de los aportes que sumaron las personas que no habían asistido al primer encuentro, y de la información que trajeron quienes realizaron indagaciones en el tiempo transcurrido desde el primer encuentro, realizamos nuevas tarjetas y se agregaron a la sistematización colectiva en las columnas correspondientes. Se incorporaron apellidos de primeros pobladores, lugares significativos, algunos saberes y algo muy importante, una de las participantes del primer encuentro compartió una versión sobre el origen del nombre del paraje que recuperó a partir de una entrevista a un antiguo poblador: 
Se llama La Armonía por la unión de la gente que se encontraba en este lugar. Aquí se trataban entre criollos y aborígenes, entre gente de Salta y comerciantes que iban desde el sur hacia el norte, más la gente que se estaba afincando en la zona. Esta es la razón del nombre del paraje: es La Armonía porque era un lugar de reunión, en el que la gente intercambiaba productos y creaba vínculos sociales. (Aporte de una participante del taller que entrevistó a un poblador antiguo)

En la convocatoria recordamos a los participantes que asistan con una fotografía, documento, carta, objeto, recorte de diario o imagen que considere significativa para su historia personal, familiar y/o comunitaria. A este momento lo llamamos contando historias a partir de fotos, imágenes y objetos. Se compartieron en ronda, realizando un breve relato contando qué es, de dónde lo sacó, qué significa para ella o él, su familia y/o la comunidad. Se realizaron registros de estos relatos y se escanearon algunos documentos.

Continuamos con la Dinámica del Billete ${ }^{17}$, ejercicio con el que buscamos problematizar el contexto actual en el cual la comunidad ve afectada su vida cotidiana por múltiples iniciativas y políticas relacionadas al fomento de la actividad turística. A partir de interrogarnos si es posible poner precio a la memoria y al patrimonio cultural, nos propusimos facilitar experiencias que promuevan la sensibilización respecto a lo que se considera valioso e importante,

\section{DINAMICA DEL BILLETE}

- Con imágenes de billetes de distintos paises impresas

- A partir de la observación de sus características se analizaron los distintos elementos que los componen: algunos tenían imágenes relacionadas a hechos históricos, personajes destacados, animales, lugares.

- Reflexión sobre sobre el porqué de esos elementos en un billete y su importancia.

- En pequeños grupos, crear un billete propio de su paraje, que los represente en términos históricos, paisajisticos y de prácticas culturales. digno de cuidar o de recuperar (patrimonio),

a la vez de contribuir a la identificación de prácticas y expresiones culturales, del presente y del pasado.

Esta actividad resultó enriquecedora, porque al interior de cada grupo se discutió en profundidad cuáles eran los dibujos que iban a conformar su billete. En plenario se compartió la producción de cada grupo y se reflexionó sobre los elementos de cada billete. Por ejemplo, un billete tenía al frente la figura de Fernando Ramón Salcedo y tras de él se ve el puente de La Armonía, el grupo argumentó la decisión de incluir al maestro "porque es la persona que más recuerda la comunidad ${ }^{18 "}$. Al dorso dibujaron la escuela, con su mástil y la bandera, fundamentando que "es lo primero que se ve cuando se dobla el camino". Un billete elaborado por otro grupo tenía al frente la imagen de un "corredor" con lazo y su vestimenta

\footnotetext{
${ }^{17}$ Agradecemos a la profesora Alba Lucía Pérez Osorno (Medellín, Colombia) por compartirnos esta propuesta metodológica que utiliza en sus trabajos relacionados con el patrimonio cultural inmaterial de las comunidades de Antioquia.

${ }^{18}$ Lo que está entre comillas corresponde a los registros de la actividad colectiva realizados en papelógrafos.
} 
característica, "porque es una práctica que representa nuestra cultura" (registro de la actividad colectiva); al dorso, el rostro de la maestra Hilda Argañaraz y la vieja escuela con el techo de teja de palma y el mástil. Luego, hubo un debate respecto de la relación "billete", memoria y patrimonio, sobre la importancia de recuperar la historia local desde la memoria de las y los propios pobladores, de cuidar los lugares significativos y las prácticas y saberes culturales. Ante la pregunta de si es posible poner precio a alguno de estos objetos, la respuesta de todos los participantes fue un "no" rotundo: "la escuela no tiene precio, no se podría hacer un hotel porque ahí vivió mucha gente, se está comunicando a través de ella la identidad, lo representativo de La Armonía" (Registro de la actividad colectiva). Se insistió en que todo eso no tiene precio y que no se puede comprar y vender.

La "escuela vieja" fue un elemento de importancia que se repitió a lo largo del encuentro y que se vio reflejado en los "billetes". Identificado por las y los pobladores como un "lugar trascendental" al que le asignan una importancia vital, porque gran parte de la historia del paraje sucedió en y desde esa escuelita. Esta actividad fue clave porque permitió identificar referencias significativas, propuestas y prioridades de acción.

Como emergente más significativo del proceso llevado adelante durante estos meses y de esta dinámica en particular, la voluntad colectiva de reconstruir la escuela vieja con técnicas tradicionales para poner en valor el lugar y que sirva para albergar en su interior a gran parte de la memoria de esta comunidad.

Por último, realizamos con el equipo técnico del Instituto de Cultura un registro audiovisual de una recorrida con un antiguo poblador, quien nos guio y relató historias alrededor de la primera barraca del lugar construida por su abuelo y el cementerio familiar que -como ocurre con cada familia- se encuentra en distintos lugares del monte.

\section{Entre encuentros}

Diseñamos un cuaderno a modo devolución a la comunidad. Elaboramos este material con un doble propósito: por un lado, compartir con la comunidad un resumen organizado de los datos, recuerdos, saberes y expresiones culturales que surgieron de los y las participantes de estos dos primeros encuentros $y$, por otro lado, facilitar una herramienta para que la comunidad de La Armonía siga pensando, recordando, registrando y proponiendo acciones relacionadas a sus memorias, saberes y expresiones culturales. Esta es la razón de un formato tipo cuaderno, con preguntas y actividades para realizar en sus hojas en blanco y ampliar el trabajo realizado.

Es a partir de este segundo encuentro cuando se empiezan a hacer evidentes -para nosotros- las tensiones en torno a la ocupación y el uso de la tierra. Tomada la decisión de reconstruir la Escuela Vieja, surge la inquietud de parte de la comunidad educativa ${ }^{19}$ de a

\footnotetext{
${ }^{19}$ En diciembre de 2014 se celebra el acto de "Imposición de Nombre", a través de la Resolución 7104/13 del MECCyT, que otorga a la escuela el nombre del recordado maestro Fernando Ramón Salcedo.
} 
quién solicitar los permisos correspondientes para realizar estos trabajos, puesto que funcionarios del Instituto de Colonización ${ }^{20}$ y del Instituto de Turismo aseguran que las parcelas lindantes a la escuela fueron cedidas para fines turísticos y no quedaba claro si las ruinas de la Escuela Vieja estaban dentro de la parcela del Ministerio de Educación, del Instituto de Turismo o en tierras fiscales (pero de uso histórico de familias del lugar). De hecho, con financiamiento del BID, detrás de la actual escuela ya se estaban construyendo las bases de lo que será uno de los "refugios" que prevé el Master Plan Impenetrable en la zona. Buscamos información y pudimos constatar en expedientes históricos del Ministerio de Agricultura y Ganadería de la Nación que entre 1949 y 1951 se realizan trabajos de mensura en la zona y se concreta el traspaso de la Nación a la recientemente creada provincia del Chaco, de una parcela de 5 hectáreas, para usos educativos.

Sin embargo, el Instituto de Turismo afirma ser poseedor de 3 de esas 5 hectáreas, con título de propiedad por un expediente fechado en 2016. Por otra parte, en marzo de 2019, el presidente del Instituto de Colonización emite la Resolución mediante la cual resuelve rectificar "la reserva con fines de utilidad pública efectuada a favor del Ministerio de Educación por Decreto $N^{\circ}$ 9962/51, en cuanto a denominación y superficie se refiere", estableciendo efectivamente 3 hectáreas para turismo y 2 para la actual escuela, aclarando que las mismas son "factibles de ser ampliadas en caso de real necesidad". En marzo de ese año, se eleva notificación al Ministerio de Educación informando de la mencionada modificación. No obstante, tanto las y los pobladores de La Armonía en general como la comunidad educativa en particular no fueron consultados ni informados al respecto de estas disposiciones tomadas por agentes del Estado provincial. La construcción del refugio detrás de la escuela también los tomó por sorpresa, generando sensaciones de incertidumbre y zozobra respecto al destino de las tierras que ocupan desde hace más de cien años: "los vecinos estamos pintados" es una frase que escuchamos más de una vez, pronunciada por diferentes personas.

\section{Tercer encuentro}

Durante esta jornada se compartió la información sistematizada en Power Point y se hizo entrega de varias copias del cuaderno. Algunas copias quedaron en la escuela y otras se distribuyeron entre las y los presentes. Este momento nos permitió dimensionar colectivamente lo compartido. Volvimos a revisar y ampliar la sistematización. Las y los presentes ratificaron la decisión colectiva de reconstruir la Escuela Vieja. Para orientarnos a tal fin, desarrollamos una dinámica llamada "Círculo de sueños" ${ }^{21}$ que nos facilitó identificar los objetivos y proponer, participativa y creativamente, actividades para desarrollar en la

\footnotetext{
${ }^{20}$ Organismo provincial que administra y dispone de las tierras fiscales.

${ }^{21}$ Agradecemos a la narradora oral y gestora cultural Hanna Cuenca, de Bogotá, Colombia, por proponernos esta dinámica por acompañarnos en su realización.
} 
siguiente etapa. Cada participante expresó un sueño o deseo de cómo le gustaría que sea el proceso de reconstrucción de la Escuela Vieja, qué le gustaría que pase, durante y después de la reconstrucción. Anotamos estos sueños individuales en papelógrafos a la vista de todos. Se realizaron dos vueltas de sueños. Luego, los fuimos leyendo en tiempo pasado, como si ya se hubieran cumplido, pero no como sueños individuales, sino como sueños colectivos, comunitarios.

Consideramos importante compartir la transcripción textual de este ejercicio, puesto que el mismo dio sentido a toda la etapa posterior aún en proceso:

- SOBRE CÓMO QUEDARÁ LA ESCUELA: Que se haga la escuela; Que se arregle bien a la Escuela Vieja y tenga un techo nuevo; Que tenga un pequeño jardín de flores con rosas, lantanas, santa ritas y flores nativas; Que quede linda y la cuidemos entre todos; Que tenga una huerta comunitaria; Que tenga muchos juegos para niños; Que sea un museo donde los niños cuenten la historia de La Armonía; Que la escuela tenga un castillo inflable, un tobogán y una hamaca.

- PARA QUÉ RECONSTRUIR LA ESCUELA: Que la reconstrucción de la escuela sirva para la unión de todos los vecinos; Que se reconstruya la escuela para que estén reunidos todos los del paraje y también quienes lo visitan; Que la reconstrucción de la escuela una a la comunidad; Festejar con toda la comunidad la inauguración de la escuela reconstruida; Que la reconstruyamos antes de un año. Que seamos todos unidos y que cuando tengamos que trabajar, lo hagamos juntos. Y que la escuela quede linda; Que sirva para unir a alumnos, ex alumnos y a maestros al momento de reconstruir la escuela; Que cuando la escuela esté hecha allí se enseñe a hacer dulces.

- SOBRE LA HISTORIA: Que los pobladores antiguos cuenten la historia en la escuela reconstruida; Que los mayores transmitan a los más jóvenes los oficios para que se mantengan; Que los docentes acompañen a niños y padres la transmisión de la historia con amor.

Este encuentro marcó el cierre de una primera etapa del proyecto. Por lo tanto, propusimos una actividad de evaluación participativa. La llamamos el Guiso de la evaluación.

Aquí el resultado textual de esta dinámica:

¿Qué traje para el guiso?

Tiempo. Emociones. Propuestas. Opiniones. Ideas. Ganas. Orejas para escuchar. Consejos. Ganas. Expectativas. Compartir conocimientos. Curiosidad. Chistes, cuentos. Expectativas. Alegría. Belleza del lugar. Emociones. Recuerdos. Reflexiones. Expectativas. Ganas de volver. Felicidad. Mucho conocimiento del lugar y la gente. Amistad. Aprendizajes. Muchas historias para contar a los hijos y nietos. Muchos conocimientos nuevos. Ganas de ver la Escuela Vieja reconstruida.

¿Qué es lo que más me gustó?

Cuando hicimos el ejercicio de los billetes (tres personas destacaron esta actividad). El Círculo de Sueños. Escuchar al Ñato. La participación y el compromiso de la gente. La coincidencia en

\section{GUISO DE LA EVALUACIÓN}

-Imaginar que los encuentros son como hacer un guiso.

- En ronda, realizamos las siguientes preguntas: ¿Q̣ué traje para el guiso? ¿Qué es lo que más me gustó? ¿Qué no me gustó, cómo hubiera sido más rico el guiso? ¿Qué puedo aportar para mejorar?

- Anotamos las respuestas en un papelógrafo. 
la idea de reconstruir la Escuela Vieja (tres reiteraciones).

¿Cómo hubiera sido más rico y más lindo "el guiso" de los encuentros?

Que todos los encuentros hubieran sido los días de clases. Haber venido a todos los talleres. Que vinieran todas las familias desde el primer encuentro. Que estemos todos los vecinos. Que los encuentros no fueran tan distanciados. Que compartamos todos. Que vinieran más vecinos, más compromiso.

¿Qué puedo aportar para mejorar?

Ayudar en el trabajo de la reconstrucción de la Escuela Vieja. Trabajar y cocinar para los que trabajan en la reconstrucción de la escuela. Mi tiempo y mis manos. Fuerza. Trabajar. Acompañamiento. Cocinar torta y pan. Tiempo y trabajo. Armar el jardín de flores. Ganas. Colaborar con comidas, mate y torta parrilla mientras se trabaja. Compromiso. Acompañar. Ayudar.

El sentido de esta dinámica no fue solo "evaluar" el proceso hasta el momento, sino también explicitar acuerdos y compromisos de cara al futuro, concretamente a la decisión de reconstruir la escuela vieja.

\section{Segunda etapa}

Previo a la realización del primer encuentro de la segunda etapa, confeccionamos un "boletín" con lo recuperado en el círculo de sueños y logramos que se distribuya en el paraje antes de nuestra llegada. Como ya dijimos anteriormente, la reconstrucción de la Escuela Vieja implica la posibilidad de concretar varias iniciativas que van desde la creación de un "jardín de flores" a lograr "la unión de los vecinos"; desde registrar el estado actual de la escuela con dibujos de los niños y niñas hasta recuperar el archivo histórico que posee la escuela (como, por ejemplo, las actas de creación de la primera Cooperadora en 1941, el escudo de escuela nacional, etcétera). Nos propusimos como equipo acompañar esta iniciativa comunitaria, ayudar con la planificación de las tareas, con la gestión de recursos, con la obtención de los permisos necesarios y con el aporte del registro audiovisual de todo el proceso para luego editar un documental. 


\section{ETAPA II}

\section{COMUNIDAD}

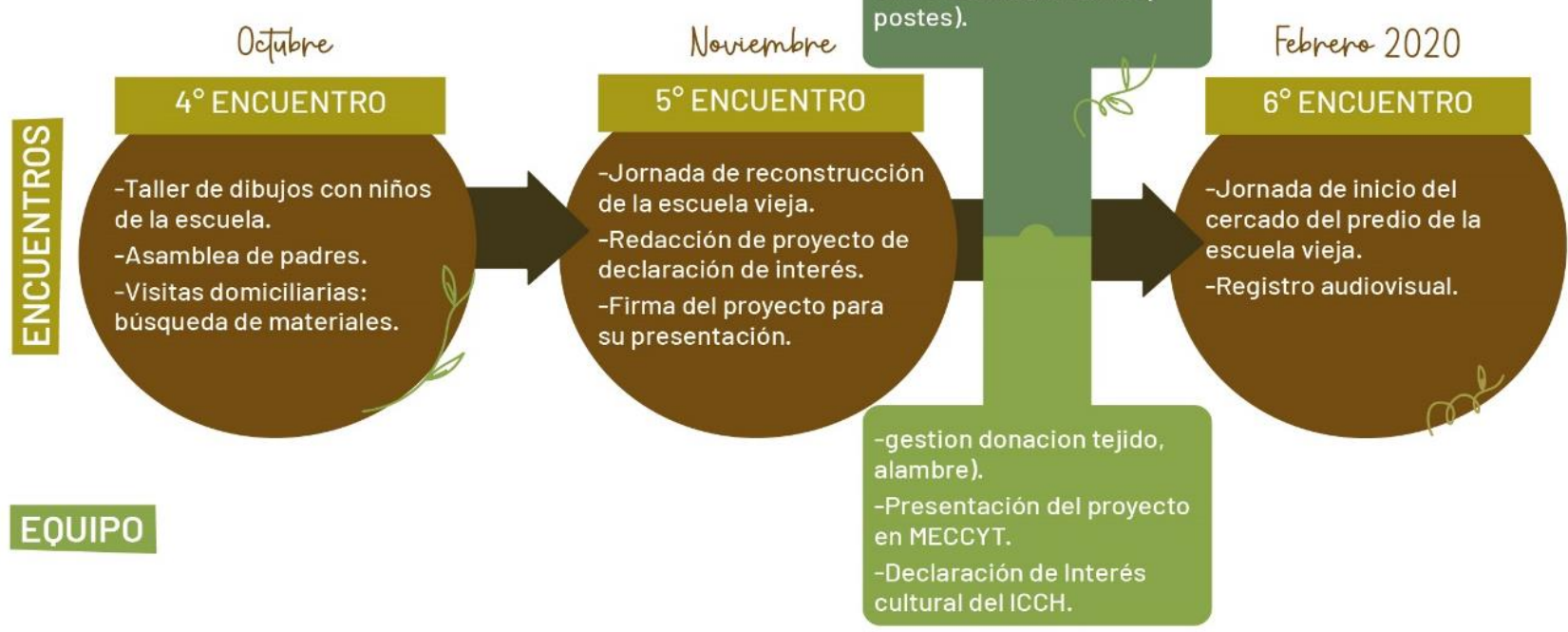

\section{Cuarto encuentro}

En el cuarto encuentro organizamos, junto a la maestra/directora (personal único) de la escuela, el taller de dibujo con las niñas y los niños para registrar, desde sus miradas, el estado actual de la Escuela Vieja. Mientras pintaban sus dibujos en un salón, realizamos una asamblea con algunas pobladoras y pobladores que venían participando de los encuentros anteriores. Los objetivos de esta asamblea fueron aclarar malentendidos que surgieron a partir de la distribución del Boletín con el "Círculo de Sueños ${ }^{22 " ~ y ~ p l a n i f i c a r ~ l a s ~ a c c i o n e s ~}$ necesarias para la reconstrucción de la Escuela Vieja. Recorriendo el predio, se realizó una evaluación del estado de los vestigios del edificio y se confeccionó una lista de los materiales necesarios para su reconstrucción. Para ello, se tuvieron en cuenta imágenes de la escuela en la época del maestro Salcedo. Con esta lista, visitamos en grupo a distintos vecinos, se aclaró el malentendido respecto al Boletín y solicitamos colaboración para el trabajo y aportes de materiales para la obra. Acordamos iniciar el proceso con una jornada de trabajo quince días después.

\section{Quinto encuentro}

\footnotetext{
${ }^{22}$ Como comentamos, el Boletín se distribuyó con los sueños redactados en tiempo pasado, como si estos ya se hubieran cumplido. Algunas personas que no asistieron a ese encuentro, al leerlo, lo interpretaron como afirmaciones, como una suerte de engaño a la población. Afortunadamente, este malentendido se aclaró y el conflicto que se suscitó sirvió para afirmar el proceso y potencializar las acciones, puesto que se logró sumar más gente para la jornada de trabajo acordada para noviembre.
} 
La jornada de reconstrucción fue el quinto encuentro. El día acordado llegamos a La Armonía temprano y ya se encontraba un grupo de cuatro pobladores trabajando en la limpieza del predio. Pasados unos minutos, llegaron cuatro pobladores más. Comenzamos a realizar registros audiovisuales y a organizar la logística para buscar y trasladar los horcones y postes que donaron algunos pobladores. El Parque Nacional El Impenetrable puso a disposición una camioneta y un acoplado. Esta es una tarea dura y solamente se pudo llevar a cabo con un trabajo de equipo organizado. Una parte del equipo salió a buscar más horcones y postes, mientras otra parte se quedó junto a la directora de la escuela redactando el pedido para solicitar la declaración de interés educativo y cultural al proyecto de restauración de la Escuela Vieja. Al finalizar la tarde, se logró la limpieza del predio y el recambio de dos horcones. Se leyó el proyecto y el mismo fue aprobado por las y los pobladores, quienes brindaron su apoyo a partir de un aval que fue firmado por los presentes y luego por otros vecinos a los que se fue a visitar.

El proyecto se denomina Reconstrucción de la Escuela Vieja de La Armonía: un espacio educativo para las memorias y las expresiones culturales comunitarias y en su fundamentación explica que responde a la iniciativa colectiva que se propone crear un espacio educativo de la memoria y las

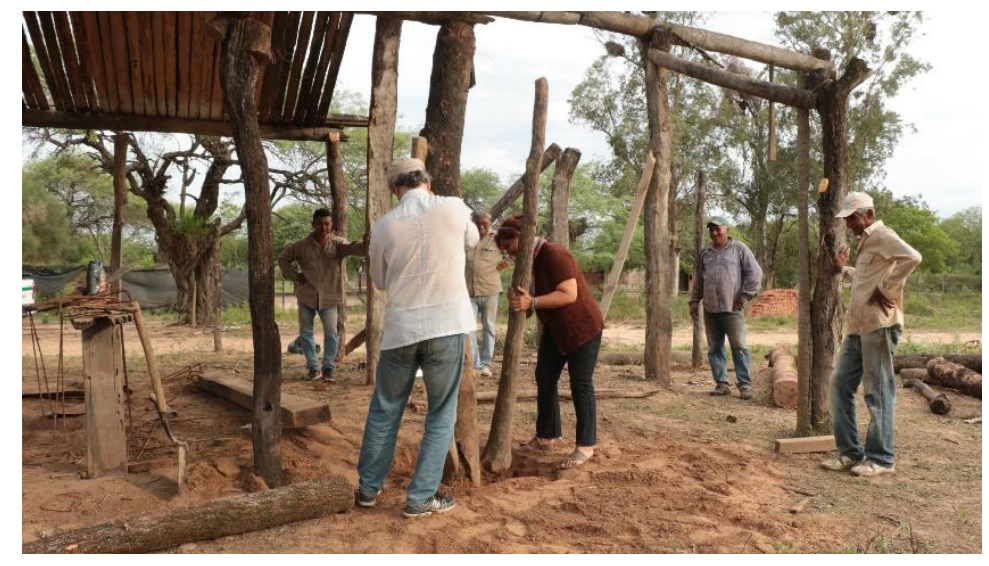
expresiones culturales de La Armonía,'a partir de la recuperación de un espacio trascendental para la vida comunitaria: la reconstrucción de la antigua escuela, construida con técnicas tradicionales en 1938 por los primeros pobladores. Se pretende que, en y desde este espacio, la memoria comunitaria de este paraje y de las zonas aledañas pueda ser revitalizada y relatada desde las voces de sus pobladores/as y transmitida de generación en generación, con el protagonismo de las niñas y niños que estudian en la escuela. Durante el mismo mes de noviembre, el proyecto fue declarado de Interés Cultural para la Provincia del Chaco. Esta declaración fue importante porque permitió gestionar recursos desde la ciudad de Resistencia con un aval potente. Así fue que en diciembre de 2019 logramos que una empresa donara los materiales necesarios para cercar el perímetro de la Escuela Vieja con alambre tejido, para evitar que se metan animales a destruir la futura restauración. Un poblador donó los postes y en febrero de 2020, en el sexto encuentro se inició el cercado y el registro audiovisual de esa tarea.

Por ASPO nacional y provincial, tuvimos que interrumpir los encuentros periódicos. No obstante, seguimos en comunicación permanente con algunos pobladores y se van buscando 
alternativas: un integrante del equipo logró una nueva financiación para obtener materiales y un poblador donó las palmas necesarias para volver a techar la escuela con su técnica original.

Durante este tiempo, las tensiones en torno al uso de la tierra han continuado. Decisiones que las y los vecinos dicen desconocer o que se comunican de manera confusa y generan sospechas o angustias en la comunidad. Recientemente, conocieron que el Instituto de Turismo acordó con CLT la ocupación de sus tres hectáreas lindantes con las escuelas (la actual y la antigua) para la realización de una escuela de oficios, proyecto que por algunas razones inquieta a algunos pobladores:

\begin{abstract}
Como te habrás enterado, Turismo agarró una parte del terreno de atrás de la escuela, trajeron unos papeles que para mí no son reales, ¿no?, pero vamos a ver cómo es en realidad y ese lugar yo lo mezquino, o lo mezquinamos entre todos, porque ese lugar, en enero y febrero, vivimos nosotros ahí, pasamos a bañarse, descansamos ahí, los chicos juegan a la orilla del río. Porque si vamos a otro lugar no tenemos donde, del otro lado está CLT, Parques tampoco no podemos ingresar, y nosotros ya no tenemos playa, digamos. Nosotros decimos siempre "la playa nuestra". No tenemos playa para pasar el verano, ¿cómo vamos a hacer si eso ya va a ser privado ${ }^{23}$ ?
\end{abstract}

El cambio de gestión del gobierno provincial en diciembre de 2019 y, por ende, de las autoridades de cada una de estas instituciones, implicó cambios en la conformación del equipo coordinador. Además, requirió volver a posicionar el interés por el proyecto y por el enfoque metodológico y las tensiones que las intervenciones estatales ocasionan. En reuniones recientes entre el Instituto de Turismo y el Instituto de Cultura, el enfoque participativo se declaró como un acuerdo de base.

\title{
Reflexiones en proceso
}

Un punto interesante que pudimos constatar es que, en un contexto de ofertas abrumadoras de proyectos, talleres y capacitaciones relacionadas a las nuevas demandas e intereses depositados en la zona, la gente participó de estos encuentros sabiendo que los mismos estaban impulsados por las tres instituciones estatales gravitantes en la creación de sus nuevas problemáticas. Entendemos que esto expresa un interés genuino por recuperar sus memorias y narrar su propia historia, por identificar y registrar sus saberes y conocimientos. $Y$ en ello se equilibraron los intereses de las instituciones.

Si bien diseñamos diferentes ejercicios para lograr de manera participativa la identificación de prácticas y expresiones culturales, del presente y del pasado, que la comunidad considera significativas, entendemos que el proceso llevó a centrar las acciones y los sentipensamientos del grupo en los usos y la ocupación de la tierra. La identificación de lugares importantes y

\footnotetext{
${ }^{23}$ Transcripción textual de comunicación vía audios de WhatsApp de una pobladora con un integrante del equipo coordinador en noviembre de 2020.
} 
sucesos históricos significativos, a través de mapeos, hizo visible la tensión respecto del uso que se pretende realizar de esas tierras, en función de intereses turísticos para el desarrollo y/o de las acciones de conservación. ¿Cómo considerar los cementerios familiares distribuidos por distintas partes del monte, el antiguo corral comunitario, la histórica pista de aviación construida por la comunidad con el maestro Salcedo? Podemos tratar estos relatos solo como emergentes de un ejercicio de memoria romantizada ${ }^{24}$ para exponer en el museo, pero, sin embargo, también se puede dar lugar a la emergencia de memorias y a profundizar sobre la situación presente en que la mirada de ese pasado es actualizada: "las memorias son menos una restitución fiel del pasado que una reconstrucción continuamente actualizada del mismo" (Candau, 2008: 9).

En este sentido, la memoria puesta en la escuela vieja es indisoluble de la parcela de tierra que albergó a la misma (en donde actualmente se encuentran sus vestigios) y que concentra los múltiples usos comunitarios que hoy deben cambiar, porque ese territorio se adecua a las necesidades del turismo por llegar.

La propiedad legal de una de las parcelas que hoy tensiona a la comunidad fue otorgada por el Instituto de Colonización al Instituto de Turismo, y este define su uso, amparado en esa legalidad. Este es un procedimiento que se considera exclusivamente administrativo y sin dar lugar para el conocimiento de los procesos históricos del poblamiento de esta zona, del uso y posesión de familias campesinas establecidas en estos parajes desde ya hace más de un siglo, a considerar que bajo tierra yacen dos y hasta tres generaciones de sus ancestros.

La presencia de CLT incorpora más complejidades a estas disputas. La creación del Parque Nacional El Impenetrable acentuó estas tensiones en torno al uso de la tierra, por el hecho de que las tierras lindantes al mismo adquieren un nuevo valor a partir de los diferentes intereses que allí se comienzan a concentrar: turísticos, de conservación, científicos e inmobiliarios. Recientemente, Turismo autorizó a CLT a construir y gestionar, en esa parcela de tres hectáreas, una escuela de oficios que es pensada como un beneficio para la comunidad. ¿Quién irá a esa escuela si nace sin el acuerdo de la propia comunidad? ¿Deberán cambiarse los destinatarios, ampliarlos a "otros" que no se detengan en el amparo de ese pasado? La memoria deja entonces de ser un punto de acuerdo entre las instituciones estatales, se aleja de su rol expositivo para acceder a un pasado que quizás ya no está y se instala como fuerza de disputa por el presente.

Un ejemplo de esto es que del conjunto de sueños consignados en el ejercicio "Círculo de Sueños" emerge con suma claridad que el deseo de reconstruir la Escuela Vieja va más allá de la idea de conservar un edificio de importancia histórica para la comunidad, que

\footnotetext{
${ }^{24}$ Si sostenemos que la memoria como la identidad son procesos permanentes, es porque asumimos la posición de que las mismas no pueden ser contenidas en una selección estática de contenidos que se exponen. Sin embargo, la tentación a su registro como posibilidad de su reconocimiento, fortalecimiento, salvaguardia, muchas veces convierte esa tarea en un fin en sí mismo, aséptico, porque quién puede oponerse en este tiempo histórico a dudar del valor de las culturas populares.
} 
trasciende el sentido de tener un lugar especial que les identifique para recibir a las y los visitantes. La decisión de emprender esta iniciativa cobra real importancia porque la comunidad ve en ella la oportunidad de fortalecer sus vínculos, de tener una motivación para organizarse, para unirse en un sitio común y a través de unas memorias compartidas que les son significativas, posicionarse de manera más sólida en las negociaciones a las que se ve obligada a partir de este nuevo contexto.

Desde aquí también es necesario ver la historia de la legalidad para reconocerle -o nolegitimidad a las disposiciones de posesión y gestión de estas tierras que decide el Estado provincial a través del Instituto de Colonización.

Creemos que la importancia de implementar procesos participativos reales, vinculados a la $\mathrm{RCH}$ y la IAP, resulta un pequeño aporte a la organización comunitaria frente a relaciones de fuerza desiguales que disputan el poder de decidir sobre el destino de estos parajes y de estas poblaciones. Disputas en las que las voces de los pobladores debieran escucharse a través de espacios adecuados y respetuosos, considerando los tiempos necesarios para brindar la información detallada y que la misma pueda ser ampliada, analizada, ofreciendo y construyendo alternativas de acción que permitan a las comunidades decidir y crear los futuros en los que quieren y desean vivir.

Mapear cementerios, lugares trascendentales del pasado y del presente de la vida comunitaria, decidir poner en valor la Escuela Vieja, soñar con que la misma "tenga un pequeño jardín de flores con rosas, lantanas, santa ritas y flores nativas", y con que se transforme en un sitio de memoria desde donde narrar con voz propia las historias y saberes que se decidan compartir, son formas colectivas de entrar en esta disputa por las nuevas formas de gestionar este territorio y los procesos de socialización con actores institucionales del Estado, ONG, técnicos y turistas que se incorporaron a la vida cotidiana de esta comunidad de manera ya irreversible.

Por todo esto, desarrollar proyectos de esta índole significa una apuesta política que exige la incorporación de metodologías y procesos participativos sinceros. Pero, ¿alcanza con enunciarlos? Entendemos que esta situación pone de manifiesto la importancia de que el Estado de manera integral y las organizaciones involucradas en los proyectos de desarrollo turístico, urbanización y conservación respeten los procesos de consultas previas establecidos por legislación internacional, y que los mismos sean llevados a cabo a partir de procesos participativos reales, consultivos y vinculantes. Podemos constatar que aún falta mucho camino por recorrer, tanto institucional y académicamente como en el fortalecimiento de las organizaciones comunitarias de base, para que todo esto no solo sea un enunciado, sino más bien acciones concretas, situadas y comprometidas con procesos sociales y comunitarios de autonomía y emancipación.

Las acciones descritas en este trabajo tuvieron como finalidad aportar al fortalecimiento de la autonomía cultural comunitaria para acrecentar el poder de decisión y de negociación de los 
actores locales frente a los distintos tipos de intervenciones que los atraviesan (estatales, privadas y religiosas), principalmente los procesos de turistificación ya mencionados.

Creemos que la concreción gradual de este propósito permitirá mitigar los posibles impactos no deseados de estas políticas e intervenciones, hacerles frente en procesos de negociación desde un posicionamiento de poder colectivo afianzado, aprovecharlas de manera positiva y/o apropiarse de manera reflexiva de las mismas.

También es necesario reflexionar que, en el repertorio de posibilidades de esta comunidad en relación con las políticas de turismo, están presentes tanto el distanciamiento de sus prácticas culturales tradicionales como la decisión consciente de no incorporarlas ni incorporarse como oferta turística. Los agentes estatales que bregamos por el bien común asumiendo esto como fin último de las acciones estatales y no como una decisión ética personal- deberemos retomar en el sentido de cada acción, la voz del otro y centrar los debates dentro de las instituciones públicas respecto de la legalidad y la legitimidad de la acción pública. Incluimos a la universidad en ellos. Muchas veces desde allí, desde la academia, miramos alejados la gestión pública, como si no fuéramos parte de la misma. Una distancia que también requiere un proceso de ruptura profundo. Es innegable que la creación del Parque Nacional El Impenetrable activó el interés por este extenso territorio y por primera vez la Universidad (UNNE) dispuso de una convocatoria específica de proyectos de investigación y acción destinados al mismo. Hay en esa gran extensión múltiples comunidades como La Armonía, ¿podrán/podremos los distintos agentes estatales dar lugar a sus voces?

A partir de la implementación de este proyecto, del proceso comunitario que se acompañó y de los primeros resultados que se pudieron registrar, emergen elementos suficientes como para considerar que las memorias colectivas y compartidas son un patrimonio de los pueblos, de las comunidades; que son pertinentes y necesarios proyectos y procesos que se propongan la revitalización, la apropiación, la transmisión y el cuidado de esos aprendizajes anclados a las memorias colectivas, producto del trabajo, de los conflictos, de las luchas emprendidas colectivamente, tanto las ganadas como las perdidas, de las celebraciones, de los dolores y las alegrías compartidas.

El Estado ha detentado un poder simbólico para definir las memorias colectivas en torno a la nación, urge asumir el desafío de redefinir su rol entorno a las memorias locales: ¿Es necesaria la legitimidad estatal de la memoria comunitaria? Quizá pueda modificarse la perspectiva unificadora homogeneizadora, para dar lugar al fortalecimiento de grupos comunitarios en pos de un ejercicio más plural dentro de la democracia capitalista.

Por cerrar y abrir al mismo tiempo, nos permitimos reflexionar de manera crítica sobre nuestro rol como acompañantes de este proceso, las tensiones y contradicciones que nos genera el hecho de escribir este artículo que manifiesta, de alguna manera, una mirada analítica que se despega en cierta medida del enfoque participativo con el que se llevó 
adelante esta experiencia. ¿La autoría intelectual, las atribuciones de quiénes y cómo interpretan y analizan los procesos vividos de manera colectiva manifiestan limitaciones e incoherencias con respecto a los enfoques participativos a la hora de producir textos académicos de este tipo? ¿Cuáles son las posibilidades reales de realizar esta tarea reflexiva de manera conjunta con la comunidad con la que se trabaja, en el contexto que determinan los tiempos académicos y de vida de quienes apostamos por estos procesos, y en la cotidianidad misma de las personas con las que trabajamos, con sus propias dinámicas y tiempos de trabajo y búsqueda del sustento?

Creemos que es necesario revisar prácticas institucionales y actitudes profesionales para que nos sea más sencillo el aventurarnos a imaginar y crear estrategias que nos permitan disminuir estas contradicciones, tensiones y angustias, Sobre todo para quienes creemos que los procesos participativos son necesarios para hacer más democráticas a las democracias y que contribuyen de manera efectiva para que estas tengan, también, sus propios "pequeños jardines de flores".

\section{Bibliografía}

Candau, J. (2008). Memoria e Identidad (1 ${ }^{\mathrm{a}} \mathrm{ed}$.) Buenos Aires: Editorial Del Sol.

Cendales, L. y Torres Carrillo, A. (2001). Recordar es vivir. Algunas técnicas para reactivar la memoria colectiva Rev. Aportes Investigación Innovación. Bogotá: Dimensión Educativa.

Fals Borda, O. (1985). Conocimiento y poder popular: lecciones con campesinos de Nicaragua, México y Colombia. Bogotá: Siglo XXI Editores.

Fals Borda, O.; Brandao, C. y Cetrulo, R. (1991). Investigación participativa ( $3^{\mathrm{a}}$ ed.) Montevideo: Instituto del Hombre. Ediciones de la Banda Oriental.

García Canclini, N. (2004). Diferentes, desiguales y desconectados. Mapas de la interculturalidad (1 ${ }^{\mathrm{a}}$ ed.) Barcelona: Editorial Gedisa.

Ghiso, A. (2016). Diálogos y participación como generadores de saberes. Revista Aportes, 60. Educación popular: trayectos, convergencias y emergencias, Dimensión Educativa.

(2017). Intervención en las "Jornadas de Patrimonio y Participación: encuentro convivencial de experiencias. Colombia-Argentina 2017", realizadas en Medellín, Colombia. Audio disponible en:

\section{https://archive.org/details/jpp2017/BbAlfredoManuelGhiso.mp3}

Grossberg, L. (2012). Estudios culturales en tiempo futuro: Cómo es el trabajo intelectual que requiere el mundo de hoy $\left(1^{\mathrm{a}}\right.$ ed.) Buenos Aires: Siglo Veintiuno Editores.

Lechner, N. (2002). Las sombras del mañana. La dimensión subjetiva de la política (1 ${ }^{\mathrm{a}} \mathrm{ed}$.) Santiago, Chile: LOM Editores SA.

Mato, D. (2002). Estudios y otras prácticas latinoamericanas en cultura y poder. En Mato, D. (coord.) Estudios y otras prácticas latinoamericanas en cultura y poder. Caracas: Consejo Latinoamericano de Ciencias Sociales (Clacso) y CEAP, FACES, Universidad Central de Venezuela. 
Villasante, T.R.; Hernández Loli y otros (2019). Estrategias Transformadoras. Cómo potenciar la creatividad colaborativa desde los movimientos y procesos sociales. Cimas.

Vargas, L.; Bustillos, G. y Marfán, M. (1987). Técnicas Participativas para la Educación Popular. Tomo I. Chile: Centro de estudios y publicaciones Alforja y CIDE. 